OPEN ACCESS

Edited by:

Sarah Irène Bonnet, Institut National de la Recherche

Agronomique (INRA), France

Reviewed by:

Sara Moutailler,

Agence Nationale de Sécurité

Sanitaire de l'Alimentation, de

l'Environnement et du Travail (ANSES),

France

Kelly Brayton

Washington State University,

United States

*Correspondence:

Nicholas Johnson

nick.johnson@apha.gsi.gov.uk

Received: 19 April 2017 Accepted: 19 June 2017

Published: 11 July 2017

Citation:

Mansfield KL, Jizhou L, Phipps LP and Johnson N (2017) Emerging

Tick-Borne Viruses in the Twenty-First

Century.

Front. Cell. Infect. Microbiol. 7:298.

doi: 10.3389/fcimb.2017.00298

\section{Emerging Tick-Borne Viruses in the Twenty-First Century}

\author{
Karen L. Mansfield ${ }^{1,2}$, Lv Jizhou ${ }^{1,3}$, L. Paul Phipps ${ }^{1}$ and Nicholas Johnson ${ }^{1,4 *}$ \\ ${ }^{1}$ Animal and Plant Health Agency, Addlestone, United Kingdom, ${ }^{2}$ Institute of Infection and Global Health, University of \\ Liverpool, Liverpool, United Kingdom, ${ }^{3}$ Chinese Academy of Inspection and Quarantine, Beijing, China, ${ }^{4}$ Faculty of Health \\ and Medicine, University of Surrey, Guildford, United Kingdom
}

Ticks, as a group, are second only to mosquitoes as vectors of pathogens to humans and are the primary vector for pathogens of livestock, companion animals, and wildlife. The role of ticks in the transmission of viruses has been known for over 100 years and yet new pathogenic viruses are still being detected and known viruses are continually spreading to new geographic locations. Partly as a result of their novelty, tick-virus interactions are at an early stage in understanding. For some viruses, even the principal tick-vector is not known. It is likely that tick-borne viruses will continue to emerge and challenge public and veterinary health long into the twenty-first century. However, studies focusing on tick saliva, a critical component of tick feeding, virus transmission, and a target for control of ticks and tick-borne diseases, point toward solutions to emerging viruses. The aim of this review is to describe some currently emerging tick-borne diseases, their causative viruses, and to discuss research on virus-tick interactions. Through focus on this area, future protein targets for intervention and vaccine development may be identified.

Keywords: tick, virus, emerging, transmission

\section{INTRODUCTION}

Many arthropods, including ticks, transmit diseases that cause morbidity, and mortality amongst humans, livestock, companion animals, and/or wildlife. This in turn can cause major economic costs particularly to the owners of livestock affected by disease. The relationship between the tick, its host and pathogens has been shown to be complex and each may benefit or suffer detrimental effects due to the combination of physiological and immune mediated processes each elicits during infestation and infection (de la Fuente et al., 2016). Viruses form a major constituency of the pathogens transmitted by ticks (for review see Labuda and Nuttall, 2004). Although, the presence of microorganisms in ticks appears to have little impact on the tick, presumably there is an energetic cost to harboring them and studies have demonstrated that ticks do respond in a coordinated fashion to infection with bacterial (Mercado-Curiel et al., 2011; Ayllón et al., 2015) and protozoal (Antunes et al., 2012) pathogens. Recent studies using in vitro models are beginning to identify transcriptional responses in ticks cell during infection with viruses (Mansfield et al., 2017).

Viruses that are transmitted by ticks belong to a range of virus families with different characteristics and tick vectors. One of the first tick-borne viruses identified was the flavivirus, louping ill virus, the causative agent of encephalitis in sheep and grouse, a disease recognized in livestock for hundreds of years. The demonstration that ticks were the source of infection for the virus was described almost 100 years ago (Stockman, 1918). Since this time, many more pathogenic viruses have been identified around the world. However, new examples of emerging tick-borne viral diseases that affect man are constantly being reported. Another striking feature 
that favors pathogen transmission by ticks is the multi-stage lifecycle of ticks. Most species of Ixodid ticks have three states, larva, nymph and adult that each requires a blood-meal, sometimes requiring days to complete, in order to develop to the next stage. Argasid ticks, such as Ornithodoros sp. by contrast only require minutes to feed but each stage may feed multiple times. This ensures that the tick can become infected at any stage of its lifecycle and that infection persists through each developmental stage via transstadial transmission (Karbowiak et al., 2016) and then has the opportunity to transmit that virus back to a mammalian host (Figure 1). When blood feeding requires attachment to the host for a number of days, this provides ample opportunity for transfer of virus from tick to host within infected saliva. Horizontal transmission occurs following consumption of blood from an infected mammalian host, whilst co-feeding is a form of transmission that occurs when multiple ticks feed in close proximity enabling virus to transfer between ticks without infection in the host (Jones et al., 1987). Vertical transmission of pathogens between generations of ticks has been observed (transovarial transmission) for viruses such as tickborne encephalitis virus (Reháček, 1962) and African swine fever virus (Rennie et al., 2001).

Currently, there are no effective therapeutic agents or vaccines for many tick-borne viruses with the exception of vaccines for louping ill virus, tick-borne encephalitis virus, and Kyasanur Forest disease virus, thus avoidance or control of the vector are the principal means of preventing disease. Emerging tick-borne diseases that affect humans and livestock will continue to challenge public and veterinary health. Most current research is limited to a small number of Ixodid tick species, mainly Ixodes scapularis and Ixodes ricinus, vectors of pathogens such as Borrelia burgdorferi (sensu stricto and sensu lato), Anaplasma phagocytophilum, and tick-borne encephalitis virus, a virus that is currently increasing in range across Europe (Mansfield et al., 2009). However, with over 900 species of ticks in the world (Horak et al., 2002), many capable of transmitting viruses, future research on the interactions between the pathogen, its vector and the mammalian host will need to consider a greater number of virus-tick associations. This article provides an overview of some of the emerging tick-borne viruses (summarized in Table $\mathbf{1}$ and located in Figure 2) that have arisen in the twenty-first century.

\section{EMERGING TICK-BORNE BUNYAVIRUSES}

\section{Emergence of Severe Fever with Thrombocytopenia Syndrome Virus in China}

Severe fever with thrombocytopenia syndrome (SFTS) was first documented in humans in 2007 when three patients were admitted to a hospital in Henan Province, China, with acute fever and severe leucopenia (Liu et al., 2014). Further cases were reported in Henan and Hubei provinces between 2008 and 2010

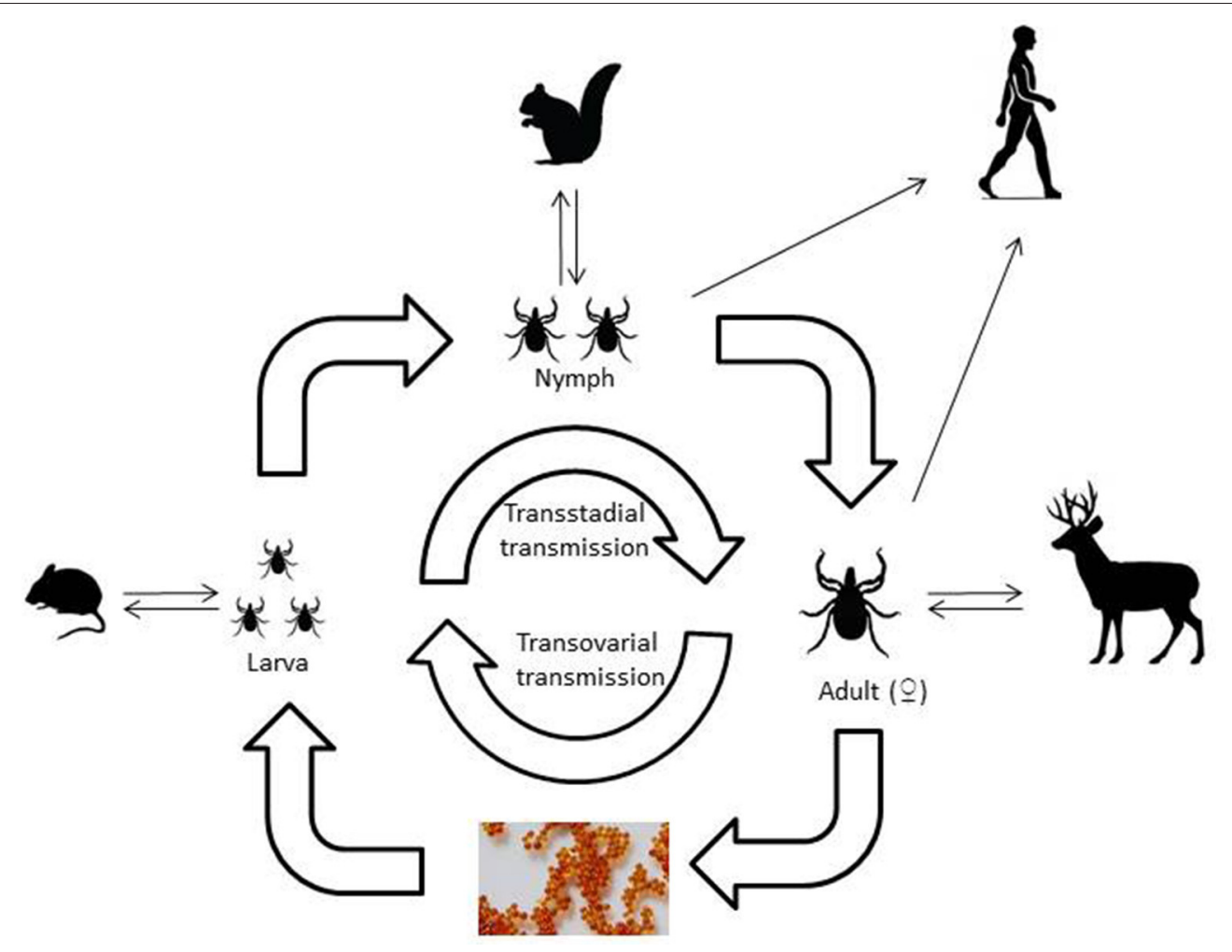

FIGURE 1 | A schematic of the three host /xodid tick lifecycle illustrating the type of vertebrate hosts involved in each life stage of the tick. 
TABLE 1 | Summary of emerging viruses discussed in this review.

\begin{tabular}{|c|c|c|c|c|c|}
\hline Virus & Abbreviation & $\begin{array}{l}\text { Classification (family, } \\
\text { genus) }\end{array}$ & Description of genome & Distribution & Primary tick vector \\
\hline $\begin{array}{l}\text { Severe Fever with Thrombocytopenia } \\
\text { syndrome virus }\end{array}$ & SFTSV & $\begin{array}{l}\text { Bunyaviridae, } \\
\text { Phlebovirus }\end{array}$ & $\begin{array}{l}\text { Tri-segmented negative } \\
\text { strand RNA }\end{array}$ & East Asia, North America & Haemaphysalis longicornis ${ }^{a}$ \\
\hline Heartland virus & HRTV & $\begin{array}{l}\text { Bunyaviridae, } \\
\text { Phlebovirus }\end{array}$ & $\begin{array}{l}\text { Tri-segmented negative } \\
\text { strand RNA }\end{array}$ & North America & Amblyomma americanum \\
\hline $\begin{array}{l}\text { Crimean congo haemorrhagic fever } \\
\text { virus }\end{array}$ & CCHFV & Bunyaviridae, Nairovirus & $\begin{array}{l}\text { Tri-segmented negative } \\
\text { strand RNA }\end{array}$ & $\begin{array}{l}\text { Africa, Central Asia, } \\
\text { Mediterranean Basin }\end{array}$ & Hyalomma marginatum \\
\hline Deer tick virus & DTV & Flaviviridae, Flavivirus & Positive strand RNA & North America & Ixodes scapularis \\
\hline Kyasunar forest disease virus & KFDV & Flaviviridae, Flavivirus & Positive strand RNA & India & Haemaphysalis spinigera \\
\hline Alkhurma haemorrhagic fever virus & AHFV & Flaviviridae, Flavivirus & Positive strand RNA & Saudi Arabia & Ornithidoros savigny \\
\hline African swine fever virus & ASFV & Asfarviridae, Asfivirus & Double-stranded DNA & $\begin{array}{l}\text { Africa, Central Europe, } \\
\text { Sardinia }\end{array}$ & Ornithodoros moubata ${ }^{\mathrm{C}}$ \\
\hline
\end{tabular}

aln China.

${ }^{b}$ In North America.

${ }^{c}$ In Africa.
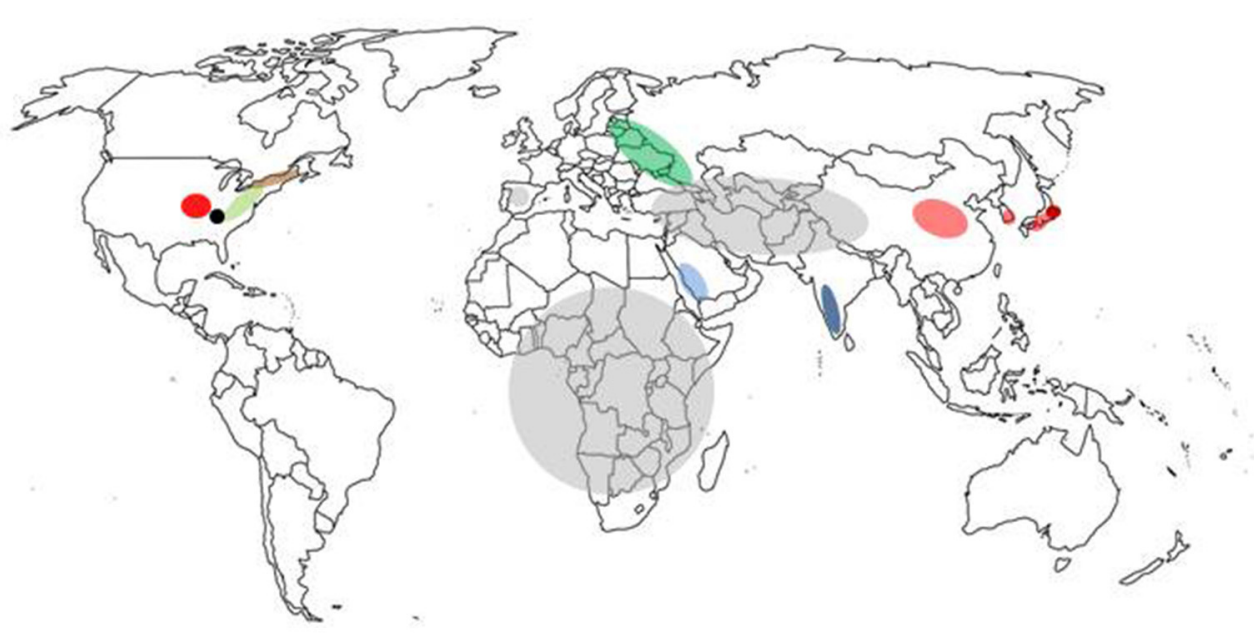

FIGURE 2 | Map of the world showing location of tick-borne disease outbreaks caused by emerging viruses. The regions marked are severe fever and thrombocytopenia syndrome virus (pale red), Heartlands virus (red), Crimean-Congo haemorrhagic fever virus (gray), Kysanur Forest disease virus (blue), Alkurma haemorrhagic fever virus (light blue), Powassan virus (brown), deer tick virus (pale green), Bourbon virus (black), Tofla virus (brown), and African swine fever virus (green).

with a similar clinical presentation and a case-fatality rate of over $10 \%$. In 2009 , the etiological agent of these infections was isolated from a patient's blood during the outbreaks of SFTS in Xinyang City in Henan province and identified as a bunyavirus related to viruses in the genus Phlebovirus (Zhang et al., 2012a,b; Lam et al., 2013). The virus was subsequently named severe fever with thrombocytopenia syndrome virus (SFTSV). Phleboviruses belong to the family Bunyaviridae, characterized by viruses with a segmented single-stranded negative sense genome divided into three segments, a small (S), medium (M), and large (L) segment coding for the nucleoprotein $(\mathrm{N})$, surface glycoproteins (Gn/Gc), and RNA-dependent RNA polymerase (L), respectively. Related viruses include the mosquito-borne Rift Valley fever virus (Mansfield et al., 2015), the sandfly-borne Toscana virus (Charrel et al., 2012), and the tick-borne Uukuniemi virus (Matsuno et al., 2015). At present, infections with SFTSV have been reported in at least 13 provinces in China, including Henan, Hubei, Anhui, Shandong, Jiangsu, and Zhejiang (Li, 2013). Preliminary investigation of the first outbreak revealed that patients with SFTS were predominantly individuals who worked outdoors such as farmers indicating a rural source for the infection. Numerous patients presented with a history of tick bites (Zhang et al., 2012a). Subsequently, cases of SFTS were reported in North Korea, South Korea, and Japan (Liu et al., 2014).

In order to identify the reservoir of SFTSV, ticks were collected from livestock around the localities where patients originated and SFTSV was detected in Haemaphysalis longicornis (Zhang and $\mathrm{Xu}, 2016)$. Further surveys of $H$. longicornis provided strong 
evidence that this tick species was the definitive reservoir and vector responsible for SFTSV transmission to humans working in rural locations (Zhang et al., 2012b). Experimental studies also demonstrated transstadial transmission of the virus between the different life stages of $H$. longicornis and transmission to mice during feeding (Luo et al., 2015). With H. longicornis being the source of infection and associated with feeding on livestock, it was highly likely that domestic animals would be exposed to infection and seroprevalence studies in China have now confirmed this (Zhang and $\mathrm{Xu}, 2016$ ). However, disease in livestock has not been reported suggesting that humans are particularly susceptible to infection with SFTSV.

\section{Emergence of Heartland Virus in the USA}

Heartland virus (HRTV) was first reported in 2009 from North America when two farmers from Missouri with a clinical presentation similar to SFTS were admitted to hospital (McMullan et al., 2012). Symptoms included fever, fatigue, headache, myalgia, arthralgia, anorexia and diarrhea. The source of the infection was identified as likely resulting from tick bites, and the isolated virus shared $73 \%$ sequence identity with SFTSV by alignment of the polymerase gene. Diagnosis of HRTV infection may be challenging but can be achieved through detection of viral RNA in blood or tissue or by demonstrating a four-fold or greater increase in virus-specific plaque reduction neutralization antibody titre between acute and convalescent serum specimens (McMullan et al., 2012). Seroprevalence studies of livestock in Minnesota State reported seropositivity rates ranging from 10 to $18 \%$, for example $15.5 \%$ in cattle, suggesting widespread exposure to infected ticks (Xing et al., 2013).

Surveillance for HRTV in Missouri has identified virus in the lone star tick Amblyomma americanum (Savage et al., 2016), an abundant tick species in many regions of the United States. Transmission of virus to a vertebrate host, transstadial and transovarial transmission between lifecycle stages has been demonstrated in A. americanum (Godsey et al., 2016). Both SFTSV and HRTV are related phleboviruses and have emerged in the past 10 years. However, the viruses exist in different tick species and have emerged in different continents. Human encroachment, probably combined with environmental conditions that influence both tick abundance and behavior may have led to the simultaneous emergence of these viruses.

\section{The Spread of Crimean Congo Haemorrhagic Fever Virus around the Mediterranean Basin}

The virus now known as Crimean Congo Haemorrhagic fever virus (CCHFV) was first described during an outbreak of haemorrhagic fever in Red Army soldiers in the Crimea during the final years of the Second World War (Ergönül, 2006). This virus was shown to be antigenically similar to a second virus isolated from a human in what is now the Democratic Republic of the Congo (Simpson et al., 1967). Worldwide, many tick species have been found infected with CCHFV and could be implicated in transmission of this virus (Mertens et al., 2013). The virus is primarily transmitted by ticks of the genus Hyalomma (Morikawa et al., 2007). By the late twentieth century, CCHFV had one of the most extensive distributions of any tick-borne virus with infections being reported from the Middle East, Asia, and sub-Saharan Africa. However, during the late twentieth and early twenty-first century, cases of CCHFV have been reported in new geographical locations around the Mediterranean Basin. CCHFV belongs to the family Bunyaviridae, genus Nairovirus. Other members of this genus include Hazara virus and Nairobi sheep disease virus. The virus genome is a tri-segmented negative sense RNA genome that encodes four structural proteins, the nucleoprotein $(\mathrm{N})$, glycoproteins (GN and GC), and the RNA-dependent RNA polymerase (L). The virus is particularly virulent for humans but has little or no pathogenic effect on livestock. Infection following a tick bite is followed by a short incubation period of between 3 and 7 days leading to a brief febrile illness characterized by fever, headache and myalgia. Haemorrhagic manifestations of disease develop 4-5 days after the development of fever and include bleeding from the nose, gastrointestinal system and urinary tract. The fatality rate ranges from 3 to $30 \%$. Treatment is supportive, including replacement of fluids and blood constituents. There is no licensed antiviral treatment or licensed vaccine for CCHF.

Reports of infection around the Mediterranean Basin began around 2002 with cases reported in Turkey (Karti et al., 2004) and the Balkans (Papa et al., 2005). In Europe, the main tick vector is Hy. marginatum, a species found throughout the Iberian Peninsula, southern France, Italy, the Balkans, and Turkey. In 2010, the virus was detected in Hy. lusitanicum ticks in Spain (Estrada-Peña et al., 2012), followed 6 years later with two human cases of autochthonous transmission (Garcia Rada, 2016). Phylogenetic analysis of virus detected in ticks indicated that the virus present in Spain shared greater identity with CCHFV in West Africa than that spreading in the Balkans. This suggested that it was a separate introduction into Europe with the most likely mechanism of entry being by tick-infested migrating birds (Estrada-Peña et al., 2012; Palomar et al., 2016). Hy. marginatum have been detected on birds migrating into Europe on numerous occasions (Capek et al., 2014) including as far north as the United Kingdom (Jameson et al., 2012). It is likely that the severity of the winters prevents establishment of this tick species in countries of northern Europe. However, the existence of populations of Hyalomma spp. in Spain, Portugal, France, and Italy puts these countries at greater risk of CCHFV persisting if introduced.

\section{EMERGING TICK-BORNE FLAVIVIRUSES Interstate Spread of Kyasanur Forest Virus in India}

Kyasanur Forest disease virus (KFDV) was isolated following an outbreak of haemorrhagic fever amongst villagers living in the Kyasanur Forest area in 1957 (Work and Trapido, 1957). The Forest is found in the Shimoga distict of Karnataka State in the south-west of India and has been the epicenter of the disease ever since with between 400 and 500 human cases reported annually (Holbrook, 2012). Initial studies demonstrated that the virus shared similar properties to Russian spring 
summer encephalitis virus (RRSEV), a variant of tick-borne encephalitis virus. However, the main clinical manifestation of disease is haemorrhagic fever unlike the encephalitis associated with RSSEV. KFDV is a member of the genus Flavivirus, family Flaviviridae. The flaviruses consist of a positive-sense singlestranded RNA genome that codes for three structural and seven non-structural proteins. Virion particles are enveloped with a single envelope protein projecting from the virus. KFDV is closely related to Alkhurma virus (AHFV) (Charrel et al., 2007) and a virus isolated in Yunnan Province, China (Wang et al., 2009). Phylogenetic studies on KFDV and AHFV suggest that they diverged over 700 years ago (Dodd et al., 2011) and that the virus has spread slowly within Karnataka Forest, reflecting dissemination by the tick vector that primarily feeds on small to medium sized mammals. Long distance movement that has separated the progenitors of both viruses could have been mediated by infected ticks attaching to migrating birds (Mehla et al., 2009).

The association with tick-borne viruses suggested a tick vector as the source of infection. Another early observation was mortality of non-human primates such as macaques and langurs in the area where human cases were reported. Haemaphysalis spp. ticks were collected from primate carcases and KFDV was isolated from Haemaphysalis spinigera (Trapido et al., 1959). Following the detection of KFDV, a second virus, Kaisodi virus, was isolated from H. spinigera sampled in India (Bhatt et al., 1966; Pavri and Casals, 1966). Haemaphysalis spp. are three-host ticks with a larval, nymphal and adult stage, each taking a blood meal prior to metamorphosis into the next stage, or egg development in the case of adult females. Although transovarial transmission of KFDV has been demonstrated in H. spinigera (Singh et al., 1963), it is the nymph and adult stages that are critical for the transmission of virus to small mammals and humans as these are the hosts favored by these life stages of the tick.

In recent years there have been reports of KFDV infections in both Karnataka province (Mourya et al., 2013; Yadav et al., 2014) and in the neighboring provinces of Kerala (Tandale et al., 2015; Sadanandane et al., 2017), Tamil Nadu and Maharashtra (Mourya and Yadav, 2016). As in previous reports, outbreaks are often preceded by disease in monkeys, and contact with carcases can lead to infection (Mourya et al., 2013).The appearance of dead monkeys, particularly target species such as the red-face bonnet monkey (Macaca radiata) and the black-faced langur (Semnopithecus entellus) are considered sentinels for the presence of KFDV at a site (Murhekar et al., 2015). The spread of KFDV in recent years could reflect further gradual spread of the virus by the tick vector, improvements in diagnosis (Mourya et al., 2012) and surveillance leading to increased frequency of reporting. Increased human exploitation of the environment leading to greater contact between humans and ticks could also contribute to this apparent spread. All of the affected regions form part of the Western Ghats, a mountain range running north-south parallel to the west coast of India. This in turn suggests that the areas affected share climatic features that are favorable to the tick vector, currently poorly studied, and that its presence could indicate a risk of KFDV. Further surveillance assessing the distribution and abundance of $H$. spinigera could reveal the true extent of KFDV in India.

\section{Emergence of Alkhurma Haemorrhagic Fever in Saudi Arabia}

Alkhurma haemorrhagic fever virus (AHFV) is a recently described tick-borne virus within the genus Flavivirus and family Flaviviridae (Horton et al., 2016). AHFV was first isolated in 1995 from a patient with haemorrhagic manifestations and fever in the city of Alkhurma in Saudi Arabia (Zaki, 1997). The whole genome of AHFV has been derived, and shares $89 \%$ sequence identity with KFDV (Charrel et al., 2001). This suggests that AHFV is a variant genotype of KFDV but with a distinct geographical distribution. AHFV is classified as biosafety level 3 agent (Charrel et al., 2007).

To investigate the tick-borne nature of AHFV, ticks were collected in both western and southern Saudi Arabia and assessed by reverse transcriptase PCR (Eraksoy, 2015). At present, AHFV has been identified in both the Argasid tick Ornithodoros savignyi and the Ixodid tick Hyalomma dromedarii (Charrel et al., 2007). As a recently emerged virus, the geographic range of AHFV is poorly understood. The wide distribution of Ornithodoros and Hyalomma spp. ticks suggests that the geographic limits of AHFV may be larger than presently assumed. The clinical case from Najran and report of AHFV in ticks from the Horn of Africa supports this view (Memish et al., 2005; Horton et al., 2016).

\section{Increased Human Incidence of Powassan Virus in New England}

Powassan virus (POWV) causes fatal encephalitis in a proportion of humans that become infected with it. Between 2013 and 2015, 8 cases of POWV encephalitis were reported from hospitals in Massachusetts and New Hampshire (Piantadosi et al., 2016). This represented the most recent evidence of an increasing trend for human cases of POWV in the United States where 9 cases were reported between 1999 and 2005 (Hinten et al., 2008). Similar trends were observed for other tick-borne diseases such as Lyme borreliosis (Bacon et al., 2008) and infection with Babesia microti (Vannier et al., 2015). POWV is a flavivirus, causing a febrile disease that can develop into severe meningoencephalitis. The virus was first reported from a fatal case in a 5 year old child in Powassan, Ontario in 1958 (McLean and Donohue, 1959).

Preliminary virological analysis suggested an association with tick-borne viruses such as (RSSEV) pointed researchers in the direction of ticks as the vector. Subsequent field surveillance detected POWV in pools of Ixodes cookei ticks and provided evidence that small mammals such as groundhogs (Marmota monax) contribute to the maintenance of virus (McLean et al., 1967). Surveillance by groups in the United States detected POWV in Colorado (Thomas et al., 1960) and New York State (Whitney and Jamnback, 1965). Numerous examples of POWV have now been isolated from the black-legged tick I. scapularis (Anderson and Armstrong, 2012) indicating that this tick species may be the most abundant vector of the virus across the eastern states of the US and southern states of Canada. In a further twist, POWV has been reported from the eastern province of Russia, Primorsky Krai, and is suspected of being established across a larger geographical area (Leonova et al., 2009; Deardorff et al., 2013). Here, the tick vector includes Ixodes spp. such as 
I. persulcatus. Phylogenetic analysis of North American POWV strains indicates that POWV diverged from a common ancestor present $\sim 500$ years ago (Pesko et al., 2010). The viruses in Russia could be an introduction due to their similarity with American isolates. One possible means of introduction of the virus could be the importation of North American species such as mink (Neovison vison) with infected ticks during the expansion of the Russian fur trade.

The number of human cases of Powassan virus infection across its range has increased in recent years. The underlying cause is unclear but could be due to an increased awareness amongst clinicians and diagnosticians. Alternatively, the increase could be related to ecological factors that lead to the increase in abundance of the tick population driven in turn by increases in the number and range of mammalian hosts such as deer. This is believed to have been behind the increase in Lyme disease, caused by B. burgdorferi, across many States in the USA (Barbour and Fish, 1993). However, the nymphal form of the tick is suspected of being responsible for most cases of transmission and abundance of this life stage is more dependent on the availability of small mammals such as rodents, for example the white-footed mouse (Peromyscus leucopus). Therefore, factors that influence rodent abundance such as predator decline, mediated by the red fox (Vulpes vulpes) for example, may have greater impact on disease transmission by ticks (Levi et al., 2012).

\section{The Spread of the Deer Tick Virus in North America}

Deer tick virus (DTV), a flavivirus in the tick-borne encephalitis group, is a genetically distinct lineage (subtype) of POWV that can cause neuroinvasive infection in humans in parts of North America. DTV was originally isolated from the Rocky Mountain wood tick, Dermacentor andersoni, but is mainly found in I. scapularis collected from states in the north-east of the US (Telford et al., 1997; Aliota et al., 2014) and has since been responsible for a human case of encephalitis (Tavakoli et al., 2009). Although the first recognized human case of DTV encephalitis occurred in 1997, evidence of the causative virus, based on sequence data, was not available until 2001 (Gholam et al., 1999; Kuno et al., 2001). The DTV genome shares $84 \%$ sequence identity with POWV and $94 \%$ amino acid identity between the virus polyproteins. However, DTV and POWV are regarded as antigenically indistinguishable and the infecting virus cannot be determined by serological testing, and genotypic analysis is needed to make a definitive diagnosis. DTV is maintained in an enzootic cycle between I. scapularis and the white-footed mouse (Peromycus leucopus) (Ebel et al., 2000). Until now there have been a small number of published cases of proven DTV induced encephalitis (Kuno et al., 2001), one from Canada and three from USA. Based on detection of virus genome, prevalence with DTV ranged up to $5 \%$ in I. scapularis from several geographic areas including Hudson Valley, Nantucket Island and Prudence Island (Aliota et al., 2014). The increase in the number of human cases of Powassan virus encephalitis that have been reported since 2010 is remarkable. Most of these cases were diagnosed by serological assays (Khoury et al., 2013) and it is possible that DTV could be responsible for some of these cases.

\section{THE EMERGENCE OF ASFARVIRUS IN EUROPE}

\section{Establishment of African Swine Fever Virus in Eastern Europe}

African swine fever virus (ASFV) is the causative agent of African swine fever (ASF), an acute haemorrhagic fever that causes severe morbidity and high mortality in domestic pigs. ASFV is classified within the genus Asfivirus and family Asfarviridae, and consists of a double-stranded DNA genome coding for $\sim 150$ proteins. The genome is surrounded by a protein capsid and a hostderived envelope. Virus particles are very robust and can survive for days in the environment or months within pork meat. ASF was first described in Kenya and is found across sub-Saharan Africa (Thomson, 1985). The epidemiology of ASF in Africa is driven by two cycles. The first is sylvatic with bush pigs (Potamochoerus larvatus) and warthogs (Phacochoerus africanus) being infected following infestation with Argasid ticks of the genus Ornithodorus, particularly O. moubata. Infections in wild species do not result in clinical signs of disease. The second cycle involves infection of domestic pigs (Sus scrofa) that are highly susceptible to infection and shed virus in excreta. Initial infection is by tick bite but is then amplified by pig-to-pig transmission, either through contact or consumption of contaminated food. ASF is a notifiable disease in Europe (http://www.oie.int/animalhealth-in-the-world/oie-listed-diseases-2016/) and significant effort is directed at preventing its introduction through import control of livestock and food stuffs. Outbreaks resulting from importation have occurred in domestic pigs on a number of occasions across Europe. Significantly in the case of Sardinia, following introduction in the late 1970s. Repeated attempt to eliminate the disease have failed and the disease is endemic (Mur et al., 2016). More recently, ASFV was introduced into the Caucasus region in 2007 (Rowlands et al., 2008) and led to extensive spread into neighboring countries including Armenia, Azerbaijan, and Russia. By 2016, ASFV has been detected throughout Eastern Europe and the Baltic region. Pig-to-pig transmission appears to be the main driver for the spread of the epidemic but wild boar, a species which is also susceptible to infection, could also contribute to spread (Guinat et al., 2016). A further concern for Europe is the infection of indigenous Argasid ticks such as $O$. erraticus that are present throughout the Mediterranean Basin and Balkans, and feed preferentially on domestic pigs, although less so on wild boar (Pietschmann et al., 2016). ASFV infects and replicates in O. erraticus (Basto et al., 2006; Ribeiro et al., 2015) and has been shown to experimentally transmit ASFV to pigs (Boinas et al., 2011). Widely distributed Ixodid ticks in Europe such as I. ricinus and Dermacentor reticulatus are unable to support ASFV replication and presumably do not contribute to disease spread (de Carvalho Ferreira et al., 2014). The spread of ASFV has been primarily caused by human activities including long distance transport of 
livestock. The presence of a susceptible wildlife host, wild boar, has further complicated efforts to control the disease and it is likely that it will continue to spread across the continent.

\section{TICK SALIVA-ASSISTED TRANSMISSION AND POTENTIAL ANTIGENIC TARGETS FOR CONTROL}

The components of saliva are critical to the successful completion of a blood meal by all life stages of ticks. As a result, tick saliva is a highly complex mixture of proteins, peptides, and other bioactive compounds. Transcriptomic analysis suggests that tick feeding leads to the upregulation of thousands of protein transcripts (Karim and Ribiero, 2015; Ribeiro et al., 2017) that when secreted promote attachment to the host, inhibit host responses such as blood clotting and inhibit microbial growth (Hovius et al., 2008). Tick saliva has also been shown to promote transmission of tick-borne viruses to the mammalian host. Early studies demonstrated that salivary gland extracts (SGE) from a range of tick species enhanced transmission of Thogoto virus and TBEV to guinea-pigs (Jones et al., 1989, 1992; Labuda et al., 1993). Recent studies have shown a similar enhancement by $O$. porcinus SGE of ASFV infection in pigs (Bernard et al., 2015) and I. scapularis SGE of POWV infection in mice (Hermance and Thangamani, 2015). One mechanism suggested for this enhancement is the increased attraction of macrophages and other antigen presenting cells to the site of tick attachment. These appear to rapidly disseminate the virus throughout the mammalian host. It is also possible that rather than being passively transmitted by the tick, viruses actively modulate tick salivary gland transcripts. In a study investigating feeding by I. scapularis nymphs, infection with Langat virus modulated tick salivary gland transcriptional responses during 3 days of feeding (McNally et al., 2012). Further analysis of virus-induced transcripts could lead to the identification of those proteins that promote virus transmission and in turn could be molecular targets for tick control and prevention of virus transmission. The concept of a tick vaccine has been discussed for decades and has led to a number of approaches based on specific tick salivary proteins that have been used as vaccine formulations that inhibit tick feeding (Labuda et al., 2006; GarciaVaras et al., 2010). The advent of "omics" technologies using both the sialotranscriptome (Maruyama et al., 2017) and the proteome (Villar et al., 2017) have dramatically expanded the number of targets available for vaccine development. The application of such vaccines to livestock or even key wildlife species could provide an opportunity to suppress tick abundance and reduce the frequency of pathogen transmission in order to suppress incidence of disease.

\section{CONCLUSIONS}

The emergence of tick-borne viruses is driven by a range of factors, often inter-related, that lead to the appearance and/or increase in human or veterinary cases of disease. Ixodid tick species have multiple life stages (Figure 1) with each feeding off a different host, and often a different host species. Factors that influence each life stage will affect their ability to transmit pathogens. Key amongst these factors are those associated with the tick vector, including its presence in an area, feeding behavior, abundance, and contact with humans or livestock. Studies on TBEV suggest that co-feeding favors virus transmission between immature tick stages (larva/nymphs) and environmental factors that promote co-feeding will drive infection rates up via horizontal transmission and increase the risk of transmission to humans (Randolph et al., 1999). This leads to the paradoxical situation whereby decreases in numbers of mammalian hosts can lead to an increase in disease transmission. Seasonal variation in temperatures can also dramatically affect transmission to humans. Low temperatures in winter and warm summer temperatures between 2009 and 2012 have been identified as the reason for the increased incidence of TBEV in Sweden enhanced by co-feeding by I. ricinus on small mammals (Jaenson et al., 2012). Warm summer temperatures also encourage humans to spend more time outdoors and wear less clothing, both factors that could increase the risk of encountering ticks. The presence of large ruminants such as deer can increase the abundance of ticks and indirectly indicate risk of virus transmission (Carpi et al., 2008). Conversely, activities that reduce tick abundance will reduce virus transmission.

The distribution of a tick-borne disease is usually dictated by that of the tick vector. This appears to be the case for viruses such as CCHFV. However, when driven by anthropomorphic factors, such viruses can emerge in new locations, enabled by an alternative mechanism of transmission. This appears to have led to the emergence of ASFV in Central Europe where tick-borne transmission has been replaced by contact transmission between pigs, driven in part by the presence of wild boar (Guinat et al., 2016).

Human factors are a major influence on disease emergence. The paradigmatic example of this is the emergence of Omsk haemorrhagic fever virus in central Russia due to the importation of muskrats (Ondatra zibethicus) from North America in the nineteenth century (Ružek et al., 2010). The virus existed in the area within the $D$. reticulatus tick population but was rarely, if ever, encountered by humans. By introducing an exotic mammalian host that was highly susceptible to infection and regularly handled by humans, clusters of haemorrhagic disease occurred. A similar scenario appears to have resulted in the introduction of POWV in Eastern Russia and the activities of the farming industry in Eastern Europe has propelled the spread of ASFV. A further human factor that can increase detection rates of emerging tick-borne diseases is awareness by clinicians. Once a cluster of cases of disease have been reported, further cases come to light. However, a lack of disease awareness among clinicians and veterinarians can hamper the control of a disease epidemic, which could potentially be the case for ASFV where clinical signs can be similar to those observed with other diseases of swine (Guinat et al., 2016). Therefore, an increase in awareness and data sharing of new and emerging tick-borne diseases among medical and veterinary professionals is essential. Transnational bodies such as the World Health Organization and the World Organization for Animal Health (OIE) play a key role in 
information sharing and setting standards for disease detection and reporting.

Tick-borne diseases continue to cause a burden to both animal and human health. As the twenty-first century progresses there will certainly be more examples of tick-borne virus spread and novel virus emergence. New viruses associated with ticks are being discovered as a result of human infection, such as Bourbon virus (Kosoy et al., 2015) or before there is any association with disease such as Tofla virus (Shimada et al., 2016; de Figueiredo et al., 2017). Early recognition of those that are pathogens will be critical to their control in addition to measures to control potential tick vectors. Understanding the interactions between these emerging viruses and the tick species that transmit them to vertebrate hosts represents both a colossal challenge and a great opportunity to identify targets for future control of tickborne diseases. A greater understanding of tick feeding has identified both the complexity of the feeding process and its role in promoting pathogen transmission (Randolph, 2009). This understanding has also resulted in the identification of protein components within tick saliva that can act as antigens for vaccines

\section{REFERENCES}

Aliota, M. T., Wilczek, M. P., Peters, R. J., Ostfeld, R. S., and Kramer, L. D. (2014). The prevalence of zoonotic tick-borne pathogens in Ixodes scapularis collected in the Hudson Valley, New York State. Vector Borne Zoonotic Dis. 14, 245-250. doi: 10.1089/vbz.2013.1475

Anderson, J. F., and Armstrong, P. M. (2012). Prevalence and genetic characterisation of Powassan virus strains infecting Ixodes scapularis in Conneticut. Am. J. Trop. Med. Hyg. 87, 754-759. doi: 10.4269/ajtmh.2012.12-0294

Antunes, S., Galindo, R. C., Almazán, C., Rudenko, N., Golovchenko, M., Grubhoffer, L., et al. (2012). Functional genomics studies of Rhipicephalus (Boophilus) annulatus in response to infection with the cattle parasite, Babesia bigemina. Int. J. Parasitol. 42, 187-195. doi: 10.1016/j.ijpara.2011.12.003

Ayllón, N., Villar, M., Galindo, R. C., Kocan, K. M., Šima, R., López, R., et al. (2015). Systems biology of tissue-specific response to Anaplasma phagocytophilum reveals differentiated apoptosis in the tick vector Ixodes scapularis. PLoS Genet. 11:e1005120. doi: 10.1371/journal.pgen.1005120

Bacon, R. M., Kugeler, K. J., and Mead, P. S.(2008). Centers for Disease Control and Prevention (CDC). Surveillance for Lyme disease-United States, 1992-2006. MMWR Surveill. Sum. 57, 1-9.

Barbour, A. G., and Fish, D. (1993). The biological and social phenomenom of Lyme disease. Science 260, 1610-1616. doi: 10.1126/science.8503006

Basto, A. P., Nix, R. J., Boinas, F., Mendes, S., Silva, M. J., Cartaxeira, C., et al. (2006). Kinetics of African swine fever virus infection in Ornithodoros erraticus ticks. J. Gen. Virol. 87, 1863-1871. doi: 10.1099/vir.0.81765-0

Bernard, J., Hutet, E., Paboeuf, F., Randriamparany, T., Holzmuller, P., Lancelot, R., et al. (2015). Effect of O. porcinus tick salivary gland extract on the African swine fever virus infection in domestic pig. PLoS ONE 11:e0147869. doi: 10.1371/journal.pone.0147869

Bhatt, P. N., Kulkarni, K. G., Boshell, J., Rajagopalan, P. K., Patil, A. P., Goverdhan, M. K., et al. (1966). Kaisodi virus, a new agent isolated from Haemaphysalis spinigera in Mysore state, south India. Am. J. Trop. Med. Hyg. 15, 958-960. doi: $10.4269 /$ ajtmh.1966.15.958

Boinas, F. S., Wilson, A. J., Hutchings, G. H., Martins, C., and Dixon, L. J. (2011). The persistence of African swine fever virus in field-infected Ornithodoros erraticus during the ASF endemic period in Portugal. PLoS ONE 6:e20383. doi: 10.1371/journal.pone.0020383

Capek, M., Literak, I., Kocianova, E., Sychra, O., Najer, T., Trnka, A., et al. (2014). Ticks of the Hyalomma marginatum complex transported by that suppress tick infestation and protect against tick-borne virus transmission (Labuda et al., 2006). Such generic approaches may assist in protecting humans and livestock from emerging tick-borne viruses.

\section{AUTHOR CONTRIBUTIONS}

NJ conceived the review. KM, LJ, LP, and NJ wrote the paper. All authors reviewed the final version of the manuscript.

\section{FUNDING}

This work was funded by the European Commission Seventh Framework Programme under the "Anticipating the Global Onset of Novel Epidemics-ANTIGONE” project (\#278976).

\section{ACKNOWLEDGMENTS}

The authors would like to thank Professors Trevor Drew and Tony Fooks for constructive criticism of this manuscript.

migratory birds into Central Europe. Ticks Tick Borne Dis. 5, 489-493. doi: 10.1016/j.ttbdis.2014.03.002

Carpi, G., Cagnacci, F., Neteler, M., and Rizzoli, A. (2008). Tick infestation on roe deer in relation to geographic and remotely sensed climatic variables in a tick-borne encephalitis endemic area. Epidemiol. Infect. 136, 1416-1424. doi: 10.1017/S0950268807000039

Charrel, R. N., Bichaud, L., and de Lamballerie, X. (2012). Emergence of Toscana virus in the Mediterranean area. World J. Virol. 1, 135-141. doi: 10.5501/wjv.v1.i5.135

Charrel, R. N., Fagbo, S., Moureau, G., Alqahtani, M. H., Temmam, S., and de Lamballerie, X. (2007). Alkhurma hemorrhagic fever virus in Ornithodoros savigny ticks. Emerg. Infect. Dis. 13, 153-155. doi: 10.3201/eid1301.061094

Charrel, R. N., Zaki, A. M., Attoui, H., Fakeeh, M., Billoir, F., Yousef, A. I., et al. (2001). Complete coding sequence of the alkhurma virus, a tick-borne flavivirus causing severe hemorrhagic fever in humans in Saudi Arabia. Biochem. Biophys. Res. Comm. 287, 455-461. doi: 10.1006/bbrc.2001.5610

Deardorff, E. R., Nofchissey, R. A., Cook, J. A., Hope, A. G., Tsvetkova, A., Talbot, S. L., et al. (2013). Powassan virus in mammals, Alaska and New Mexico, USA, and Russia, 2004-2007. Emerg. Infect. Dis. 12, 2012-2016. doi: 10.3201/eid1912.130319

de Carvalho Ferreira, H. C., Tudela Zúquete, S., Wijnveld, M., Weesendorp, E., Jongejan, F., Stegeman, A., et al. (2014). No evidence of African swine fever virus replication in hard ticks. Ticks Tick Borne Dis. 5, 582-589. doi: 10.1016/j.ttbdis.2013.12.012

de Figueiredo, G. G., Amarilla, A. A., de Souza, W. M., Fumagalli, M. J., de Figueiredo, M. L., Szabó, M. P., et al. (2017). Genetic characterization of Cacipacoré virus from ticks collected in São Paulo State, Brazil. Arch. Virol. 162, 1783-1786. doi: 10.1007/s00705-017-3279-3

de la Fuente, J., Villar, M., Cabezas-Cruz, A., Estrada-Peña, A., Ayllón, N., and Alberdi, P. (2016). Tick-host-pathogen interactions: conflict and cooperation. PLoS Pathog. 12:e1005488. doi: 10.1371/journal.ppat.1005488

Dodd, K. A., Bird, B. H., Khristova, M. L., Albariño, C. G., Carroll, S. A., Comer, J. A., et al. (2011). Ancient ancestry of KFDV and AHFV revealed by complete genome analysis of viruses isolated from ticks and mammalian hosts. PLoS Negl. Trop. Dis. 5:e1352. doi: 10.1371/journal.pntd.0001352

Ebel, G. D., Campbell, E. N., Goethert, H. K., Spielman, A., and Telford, S. R. III. (2000). Enzootic transmission of deer tick virus in New England and Wisconsin. Am. J. Trop. Med. Hyg. 63, 36-42. doi: 10.4269/ajtmh.2000.63.36

Eraksoy, H. (2015). Al-khurma haemorrhagic fever. Klimik Dergisi 27, 84-94. doi: $10.5152 / \mathrm{kd} .2014 .22$ 
Ergönül, O. (2006). Crimean-congo haemorrhagic fever. Lancet Infect. Dis. 6, 203-214. doi: 10.1016/S1473-3099(06)70435-2

Estrada-Peña, A., Palomar, A. M., Santibáñez, P., Sánchez, N., Habela, M. A., Portillo, A., et al. (2012). Crimean-Congo hemorrhagic fever virus in ticks, Southwestern Europe, 2010. Emerg. Infect. Dis. 18, 179-180. doi: 10.3201/eid1801.111040

Garcia Rada, A. (2016). First outbreak of Crimean-Congo haemorrhagic fever in western Europe kills one man in Spain. BMJ 354:14891. doi: 10.1136/bmj.i4891

Garcia-Varas, G., Manzano-Román, R., Fernández-Soto, P., Encinas-Grandes, A., Oleaga, A., and Pérez-Sánchez, R. (2010). Purification and characterisation of a P-selectin-binding molecule from the salivary glands of Ornithodoros moubata that induces protective anti-tick immune responses in pigs. Int. J. Parasitol. 40, 313-326. doi: 10.1016/j.ijpara.2009.08.011

Gholam, B. I., Puksa, S., and Provias, J. P. (1999). Powassan encephalitis: a case report with neuropathology and literature review. Can. Med. Assoc. J. 161, 1419-1422.

Godsey M. S. Jr., Savage, H. M., Burkhalter, K. L., Bosco-Lauth, A. M., and Delorey, M. J. (2016). Transmission of Heartland virus (Bunyaviridae: Phlebovirus) by experimentally infected Ambylomma americanum (Acari: Ixodidae). J. Med. Entomol. 53, 1226-1233. doi: 10.1093/jme/tjw080

Guinat, C., Gogin, A., Blome, S., Keil, G., Pollin, R., Pfeiffer, D. U., et al. (2016). Transmission routes of African swine fever virus to domestic pigs: current knowledge and future direction. Vet. Rec. 178, 262-267. doi: 10.1136/vr.103593

Hermance, M. E., and Thangamani, S. (2015). Tick saliva enhances Powassan virus transmission to the host, influencing its dissemination and the course of disease. J. Virol. 89, 7852-7860. doi: 10.1128/JVI.01056-15

Hinten, S. R., Beckett, G. A., Gensheimer, K. F., Prichard, E., Courtney, T. M., Sears, S. D., et al. (2008). Increased recognition of Powassan encephalitis in the United States, 1999-2005. Vector Borne Zoonotic Dis. 8, 733-740. doi: $10.1089 /$ vbz.2008.0022

Holbrook, M. R. (2012). Kyasanur forest disease. Antiviral Res. 96, 353-362. doi: 10.1016/j.antiviral.2012.10.005

Horak, I. G., Camicas, J. L., and Keirans, J. E. (2002). The Argasidae, Ixodidae and Nuttalliellidae (Acari: Ixodida): a world list of valid tick names. Exp. Appl. Acarol. 28, 27-54. doi: 10.1023/A:1025381712339

Horton, K. C., Fahmy, N. T., Watany, N., Zayed, A., Mohamed, A., Ahmed, A. A., et al. (2016). Crimean congo hemorrhagic fever virus and alkhurma (alkhumra) virus in ticks in Djibouti. Vector Borne Zoonotic Dis. 16, 680-682. doi: $10.1089 /$ vbz.2016.1951

Hovius, J. W., Levi, M., and Fikrig, E. (2008). Salivating for knowledge: potential pharmacological agents in tick saliva. PLoS Med. 5:e43. doi: 10.1371/journal.pmed.0050043

Jaenson, T. G. T., Hjertqvist, M., Bergstrom, T., and Lundkvist, A. (2012). Why is tick-borne encephalitis increasing? A review of the key factors causing the increasing incidence of human TBE in Sweden. Parasit. Vectors 5:184. doi: 10.1186/1756-3305-5-184

Jameson, L. J., Morgan, P. J., Medlock, J. M., Watola, G., and Vaux, A. G. (2012). Importation of Hyalomma marginatum, vector of Crimean-Cong haemorrhagic fever virus, into the United Kingdom by migratory birds. Ticks Tick Borne Dis. 3, 95-99. doi: 10.1016/j.ttbdis.2011.12.002

Jones, L. D., Davies, C. R., Steele, G. M., and Nuttall, P. A. (1987). A novel mode of arbovirus transmission involving a nonviraemic host. Science 237, 775-777. doi: 10.1126/science.3616608

Jones, L. D., Hodgson, E., and Nuttall, P. A. (1989). Enhancement of virus transmission by tick salivary glands. J. Gen. Virol. 70, 1895-1898. doi: 10.1099/0022-1317-70-7-1895

Jones, L. D., Matthewson, M., and Nuttall, P. A. (1992). Saliva-activated transmission (SAT) of Thogoto virus: dynamics of SAT factor activity in the salivary glands of Rhipicephalus appendiculatus, Amblyomma variegatum, and Boophilus microplus ticks. Exp. Appl. Acarol. 13, 241-248. doi: 10.1007/BF01195081

Karbowiak, G., Biernat, B., Werszko, J., and Rychlik, L. (2016). The transstadial persistence of tick-borne encephalitis virus in Dermacentor reticulatus ticks in natural conditions. Acta Parasitol. 61, 201-203. doi: 10.1515/ap2016-0028

Karim, S., and Ribiero, J. M. (2015). An insight into the sialome of the lone star tick, Ambylomma americanum, with a glimpse on its time dependent gene expression. PLoS ONE 10:e0131292. doi: 10.1371/journal.pone.0131292
Karti, S. S., Odabasi, Z., Korten, V., Yilmaz, M., Sonmez, M., Caylan, R., et al. (2004). Crimean-congo hemorrhagic fever in Turkey. Emerg. Infect. Dis. 10, 1379-1384. doi: 10.3201/eid1008.030928

Khoury, M. Y., Hull, R. C., Bryant, P. W., Escuyer, K. L., George, K. S., Wong, S. J., et al. (2013). Diagnosis of acute deer tick virus encephalitis. Clin. Infect. Dis. 56, e40-e47. doi: 10.1093/cid/cis938

Kosoy, O. I., Lambert, A. J., Hawkinson, D. J., Patula, D. M., Goldsmith, C. S., Hunt, D. C., et al. (2015). Novel thogotovirus associated with febrile illness and death, United States, 2014. Emerg. Infect. Dis. 21, 760-764. doi: $10.3201 /$ eid 2105.150150

Kuno, G., Artsob, H., Karabatsos, N., Tsuchiya, K. R., and Chang, G. J. (2001). Genomic sequencing of deer tick virus and phylogeny of powassanrelated viruses of North America. Am. J. Trop. Med. Hyg. 65, 671-676. doi: 10.4269/ajtmh.2001.65.671

Labuda, M., Jones, L. D., Williams, T., and Nuttall, P. A. (1993). Enhancement of tick-borne encephalitis virus transmission by tick salivary gland extracts. Med. Vet. Entomol. 7, 193-196. doi: 10.1111/j.1365-2915.1993.tb00674.x

Labuda, M., and Nuttall, P. A. (2004). Tick-borne viruses. Parasitology 129, S221-S245. doi: 10.1017/S0031182004005220

Labuda, M., Trimnell, A. R., Licková, M., Kazimirová, M., Davies, G. M., Lissina, O., et al. (2006). An antivector vaccine protects against a lethal vector-borne pathogen. PLoS Pathog. 2:e27. doi: 10.1371/journal.ppat.0020027

Lam, T. T., Liu, W., Bowden, T. A., Cui, N., Zhuang, L., Liu, K., et al. (2013). Evolutionary and molecular analysis of the emergent severe fever with thrombocytopenia syndrome virus. Epidemics 1, 1-10. doi: 10.1016/j.epidem.2012.09.002

Leonova, G. N., Kondratov, I. G., Ternovoi, V. A., Romanova, E. V., Protopopova, E. V., Chausov, E. V., et al. (2009). Characterisation of Powassan viruses from Far Eastern Russia. Arch. Virol. 154, 811-820. doi: 10.1007/s00705-0090376-y

Levi, T., Kilpatrick, A. M., Mangel, M., and Wilmers, C. C. (2012). Deer, predators, and the emergence of Lyme disease. Proc. Natl. Acad. Sci. U.S.A. 109, 10942-10947. doi: 10.1073/pnas.1204536109

Li, D. X. (2013). A highly pathogenic new bunyavirus emerged in China. Emerg. Microb. Infect. 2:e1. doi: 10.1038/emi.2013.1

Liu, Q., He, B., Huang, S.-Y., Wei, F., and Zhu, X.-Q. (2014). Severe fever with thrombocytopenia syndrome, an emerging tick-borne zoonosis. Lancet Infect. Dis. 14, 763-772. doi: 10.1016/S1473-3099(14)70718-2

Luo, L. M., Zhao, L., Wen, H. L., Zhang, Z. T., Liu, J. W., Fang, L. Z., et al (2015). Haemaphysalis longicornis ticks as reservoir and vector of severe fever with thrombocytopenia syndrome in China. Emerg. Infect. Dis. 21, 1770-1776. doi: 10.3201/eid2110.150126

Mansfield, K. L., Banyard, A. C., McElhinney, L. M., Johnson, N., Horton, D. L., Hernández-Triana, L. M., et al. (2015). Rift valley fever virus: a review of diagnosis and vaccination, and implications for emergence in Europe. Vaccine 33, 5520-5531. doi: 10.1016/j.vaccine.2015.08.020

Mansfield, K. L., Cook, C., Ellis, R., Bell-Sakyi, L., Johnson, N., Alberdi, P., et al. (2017). Tick-borne pathogens induce differential expression of genes promoting cell survival and host resistence in Ixodes ricinus cells. Parasit. Vectors 10:81. doi: 10.1186/s13071-017-2011-1

Mansfield, K. L., Johnson, N., Phipps, L. P., Stephenson, J. R., Fooks, A. R., and Solomon, T. (2009). Tick-borne encephalitis virus - a review of an emerging zoonosis. J. Gen. Virol. 90, 1781-1794. doi: 10.1099/vir.0.011437-0

Maruyama, S. R., Garcia, G. R., Teixeira, F. R., Brandão, L. G., Anderson, J. M., Ribiero, J., et al. (2017). Mining a differential sialotranscriptome of Rhipicephalus microplus guides antigen discovery to formulate a vaccine that reduces tick infestations. Parasit. Vectors 10:206. doi: 10.1186/s13071-017-2136-2

Matsuno, K., Weisend, C., Kajihara, M., Williamson, B. N., Simuunza, M., Mweene, A. S., et al. (2015). Comprehensive molecular detection of tickborne phleboviruses leads to the retrospective identification of taxonomically unassigned bunyaviruses and the discovery of a novel member of the genus phlebovirus. J. Virol. 89, 594-604. doi: 10.1128/jvi.02704-14

McLean, D. M., and Donohue, L. (1959). Powassan virus: isolation of virus from a fatal case of enecephalitis. Can. Med. J. 80, 708-711.

McLean, D. M., Cobb, C., Gooderham, S. E., Smart, C. A., Wilson, A. G., and Wilson, W. E. (1967). Powassan virus: persistence of virus activity during 1966. Can. Med. J. 96, 660-664. 
McMullan, L. K., Folk, S. M., Kelly, A. J., MacNeil, A., Goldsmith, C. S., Metcalfe, M. G., et al. (2012). A new phlebovirus associated with severe febrile illness in Missouri. N. Engl. J. Med. 367, 834-841. doi: 10.1056/NEJMoa12 03378

McNally, K. L., Mitzel, D. N., Anderson, J. M., Ribeiro, J. M. C., Valenzuela, J. G., Myers, T. G., et al. (2012). Differential salivary gland transcript expression profile in Ixodes scapularis nymphs upon feeding or flavivirus infection. Tick Tick Borne Dis. 3, 18-26. doi: 10.1016/j.ttbdis.2011.09.003

Mehla, R., Kumar, S. R. P., Yadav, P., Barde, P. V., Yergolkar, P. N., Erickson, B. R., et al. (2009). Recent ancestry of Kyasanur Forest disease virus. Emerg. Infect. Dis. 15, 1431-1437. doi: 10.3201/eid1509.080759

Memish, Z. A., Balkhy, H. H., Francis, C., Cunningham, G., Hajeer, A. H., and Almuneef, M. A. (2005). Alkhumra haemorrhagic fever: case report and infection control details. Br. J. Biomed. Sci. 62, 37-39.

Mercado-Curiel, R. F., Palmer, G. H., Guerro, F. D., and Brayton, K. A. (2011). Temporal characterisation of the organ-specific Rhipicephalus microplus transcriptional response to Anaplasma marginale infection. Int. J. Parasitol. 41, 851-860. doi: 10.1016/j.ijpara.2011.03.003

Mertens, M., Schmidt, K., Ozkul, A., and Groschup, M. H. (2013). The impact of Crimean-Congo hemorrhagic fever virus on public health. Antiviral Res. 98, 248-260. doi: 10.1016/j.antiviral.2013.02.007

Morikawa, S., Saijo, M., and Kurane, I. (2007). Recent progress in molecular biology of Crimean-Congo hemorrhagic fever. Comp. Immunol. Microbiol. Infect. Dis. 30, 375-389. doi: 10.1016/j.cimid.2007.07.001

Mourya, D. T., and Yadav, P. D. (2016). Recent scenario of emergence of Kyasanur Forest disease in India and public health importance. Curr. Trop. Med. Rep. 3, 7-13. doi: 10.1007/s40475-016-0067-1

Mourya, D. T., Yadav, P. D., Mehla, R., Barde, P. V., Yergolkar, P. N., Kumar, S. R., et al. (2012). Diagnosis of Kyasanur Forest disease by nested RT-PCR, real-time RT-PCR and IgM capture ELISA. J. Virol. Methods 186, 49-54. doi: 10.1016/j.jviromet.2012.07.019

Mourya, D. T., Yadav, P. D., Sandhya, V. K., and Reddy, S. (2013). Spread of kyasanur forest disease, Bandipur Tiger Reserve, India, 2012-2013. Emerg. Infect. Dis. 19, 1540-1541. doi: 10.3201/eid1909.121884

Mur, L., Atzeni, M., Marinez-López, B., Felizani, F., Rolescu, S., and SanchezVizcaino, J. M. (2016). Thirty-five year presence of African swine fever in Sardinia: history, evolution and risk factors for disease maintenance. Transbound Emerg. Dis. 63, e165-e177. doi: 10.1111/tbed.12264

Murhekar, M. V., Kasabi, G. S., Mehendale, S. M., Mourya, D. T., Yadav, P. D., and Tandale, B. V. (2015). On the transmission pattern of Kyasanur Forest disease (KFD) in India. Infect. Dis. Pov. 4:37. doi: 10.1186/s40249-015-0066-9

Palomar, A. M., Portillo, A., Mazuelas, D., Roncero, L., Arizaga, J., Crespo, A., et al. (2016). Molecular analysis of Crimean-Congo hemorrhagic fever virus and Rickettsia in Hyalomma marginatum ticks removed from patients (Spain) and birds (Spain and Morocco), 2009-2015. Ticks Tick Borne Dis. 7, 983-987. doi: 10.1016/j.ttbdis.2016.05.004

Papa, A., Papadimitriou, E., Bozvić, B., and Antoniadis, A. (2005). Genetic characterization of the M RNA segment of a Balkan CrimeanCongo hemorrhagic fever virus strain. J. Med. Virol. 75, 466-469. doi: 10.1002/jmv.20290

Pavri, K. M., and Casals, J. (1966). Kaisodi virus, a new agent isolated from Haemaphysalis spinigera in Mysore state, South India. Am J. Trop. Med. Hyg. 15, 961-963. doi: 10.4269/ajtmh.1966.15.961

Pesko, K. N., Torres-Perez, F., Hjelle, B. L., and Ebel, G. D. (2010). Molecular epidemiology of Powassan virus in North America. J. Gen. Virol. 91, 2698-2705. doi: 10.1099/vir.0.024232-0

Piantadosi, A., Rubin, D. B., McQuillen, D. P., Hsu, L., Lederer, P. A., Ashbaugh, C. D., et al. (2016). Emerging cases of Powassan virus encephalitis in New England: clinical presentation, imaging and review of the literature. Clin. Infect. Dis. 62, 707-713. doi: 10.1093/cid/civ1005

Pietschmann, J., Mur, L., Blome, S., Beer, M., Pérez-Sánchez, R., Oleaga, A., et al. (2016). African swine fever virus transmission cycles in Central Europe: evaluation of wild boar-soft tick contacts through detection of antibodies against Ornithodoros erraticus saliva antigen. BMC Vet. Res. 12:1. doi: 10.1186/s12917-015-0629-9

Randolph, S. E. (2009). Tick-borne disease systems emerge from the shadows: the beauty lies in molecular detail, the message in epidemiology. Parasitology 136, 1403-1413. doi: 10.1017/S0031182009005782
Randolph, S. E., Mikloisová, D., Lysy, J., Rogers, D. J., and Labuda, M. (1999). Incidence from coincidence: patterns of tick infestations on rodents facilitate transmission of tick-borne encephalitis. Parasitology 118, 177-186. doi: 10.1017/S0031182098003643

Reháček, J. (1962). Transovarial transmission of tick-borne encephalitis virus by ticks. Acta Virol. 6, 220-226.

Rennie, L., Wilkinson, P. J., and Mellor, P. S. (2001). Transovarial transmission of African swine fever virus in the argasid tick Ornithodoros moubata. Med. Vet. Entomol. 15, 140-146. doi: 10.1046/j.1365-2915.2001.00282.x

Ribeiro, J. M., Slovák, M., and Francischetti, I. M. (2017). An insight into the sialome of Hyalomma excavatum. Ticks Tick Borne Dis. 8, 201-207. doi: 10.1016/j.ttbdis.2016.08.011

Ribeiro, R., Otte, J., Madeira, S., Hutchings, G. H., and Boinas, F. (2015) Experimental infection of Ornithodoros erraticus sensu stricto with two Portuguese African swine fever virus strains. Study of factors involved in the dynamics of infection in ticks. PLOS ONE 10:e0137718. doi: 10.1371/journal.pone.0137718

Rowlands, R. J., Michaud, V., Heath, L., Hutchings, G., Oura, C., Vosloo, W., et al. (2008). African swine fever virus isolate, Georgia, 2007. Emerg. Infect. Dis. 14, 1870-1874. doi: 10.3201/eid1412.080591

Rủžek, D., Yakimenko, V. V., Karan, L. S., and Tkachev, D. E. (2010). Omsk haemorrhagic fever. Lancet 376, 2104-2113. doi: 10.1016/S0140-6736(10)61120-8

Sadanandane, C., Elango, A., Marja, N., Sasidharan, P. V., Raju, K. H., and Jamblingam, P. (2017). An outbreak of Kyasanur Forest disease in the Wayanad and Malappuram districts of Kerala, India. Ticks Tick Borne Dis. 8, 25-30. doi: 10.1016/j.ttbdis.2016.09.010

Savage, H. M., Godsey, M. S. Jr., Panella, N. A., Burkhalter, K. L., Ashley, D. C., Lash, R. R., et al. (2016). Surveillance for Heartland virus (Bunyaviridae: Phlebovirus) in Missouri during 2013: first detection of virus in adults of Ambylomma americanum (Acari: Ixodidae). J. Med. Entomol. 53, 607-612. doi: 10.1093/jme/tjw028

Shimada, S., Aoki, K., Nabeshima, T., Fuxun, Y., Kurosaki, Y., Shiogama, K., et al. (2016). Tofla virus: a newly identified Nairovirus of the CrimeanCongo hemorrhagic fever group isolated from ticks in Japan. Sci. Rep. 6:20213. doi: 10.1038/srep20213

Simpson, D. I., Knight, E. M., Courtois, G., Williams, M. C., Weinbern, M. P., and Kibukamusoke, J. W. (1967). Congo virus: a hitherto undescribed virus occurring in Africa. Human isolations-clinical notes. East Afr. Med. J. 44:87.

Singh, K. R., Pavri, K., and Anderson, C. R. (1963). Experimental transovarial transmission of Kyasanur forest disease virus in Haemaphysalis spinigera. Nature 199:513. doi: 10.1038/199513a0

Stockman, S. (1918). Louping-ill. J. Comp. Pathol. Ther. 31, 137-193. doi: 10.1016/S0368-1742(18)80019-4

Tandale, B. V., Balakrishnan, A., Yadav, P. D., Marja, N., and Mourya, D. T. (2015). New focus of Kyasanur Forest disease virus activity in a tribal area in Keral, India, 2014. Infect. Dis. Pov. 4:12. doi: 10.1186/s40249-015-0044-2

Tavakoli, N. P., Wang, H., Dupuis, M., Hull, R., Ebel, G. D., Gilmore, E. J., et al. (2009). Fatal case of deer tick virus encephalitis. N. Engl. J. Med. 360, 2099-2107. doi: 10.1056/NEJMoa0806326

Telford, S. R., Armstrong, P. M., Katavolos, P., Foppa, I., Garcia, A. S. O. Wilson, M. L., et al. (1997). A new tick-borne encephalitis-like virus infecting New England deer ticks, Ixodes dammini. Emerg. Infect. Dis. 3, 165-170. doi: 10.3201/eid0302.970209

Thomas, L. A., Kennedy, R. C., and Eklund, C. M. (1960). Isolation of a virus closely related to Powasson virus from Dermacentor andersoni collected along North Cache la Poudre River, Colorado. Proc. Soc. Exp. Biol. Med. 104, 355-359. doi: 10.3181/00379727-104-25836

Thomson, G. R. (1985). The epidemiology of African swine fever: the role of free-living hosts in Africa. Ondestepoort J. Vet. Res. 52, 201-209.

Trapido, H., Rajagopalan, P. K., Work, R. H., and Varma, M. G. (1959). Kayasanur Forest disease. VIII. Isolation of Kayasanur Forest disease virus from naturally infected ticks of the genus Haemaphysalis. Indian J. Med. Res. 47, 133-138.

Vannier, E. G., Diuk-Wasser, M. A., Ben Mamoun, C., and Krause, P. J. (2015). Babesiosis. Infect. Dis. Clin. North Am. 29, 358-370. doi: $10.1016 /$ j.idc. 2015.02 .008 
Villar, M., Marina, A., and de la Fuente, J. (2017). Applying proteomics to tick vaccine development: where are we? Expert Rev. Proteomics 14, 211-221. doi: $10.1080 / 14789450.2017 .1284590$

Wang, J., Zhang, H., Fu, S., Wang, H., Ni, D., Nasci, R., et al. (2009). Isolation of Kyasanur forest disease virus from febrile patient, Yannan, China. Emerg. Infect. Dis. 15, 326-328. doi: 10.3201/eid1502.080979

Whitney, E., and Jamnback, H. (1965). The first isolations of Powassan virus in New York State. Proc. Soc. Exp. Biol. Med. 119, 432-435. doi: 10.3181/00379727-119-30202

Work, T. H., and Trapido, H. (1957). Summary of preliminary report of investigations of the virus research centre on an epidemic disease affecting forest villagers and wild monkeys in Shimoga district, Mysore. Indian J. Med. Sci. 11, 340-341.

Xing, Z., Schefers, J., Schwabenlander, M., Jiao, Y., Liang, M., Qi, X., et al. (2013). Novel bunyavirus in domestic and captive animals, Minnesota, USA. Emerg. Infect. Dis. 19, 1487-1489. doi: 10.3201/eid1908.130165

Yadav, P. D., Shete, A. M., Patil, D. Y., Sandhya, V. K., Prakash, K. S., Surgihalli, R., et al. (2014). Outbreak of Kyasanur Forest disease in Thirthahalli, Karnataka, India, 2014. Int. J. Infect. Dis. 26, 132-134. doi: 10.1016/j.ijid.2014.05.013

Zaki, A. M. (1997). Isolation of a flavivirus related to the tick-borne encephalitis complex from human cases in saudi arabia. Trans. R. Soc. Trop. Med. Hyg. 91, 179-181. doi: 10.1016/S0035-9203(97)90215-7
Zhang, Y. Z., He, Y. W., Dai, Y. A., Xiong, Y., Zheng, H., Zhou, D. J., et al. (2012a). Hemorrhagic fever caused by a novel Bunyavirus in China: pathogenesis and correlates of fatal outcome. Clin. Infect. Dis. 54, 527-533. doi: $10.1093 / \mathrm{cid} / \mathrm{cir} 804$

Zhang, Y. Z., and $\mathrm{Xu}$, J. (2016). The emergence and cross species transmission of newly discovered tick-borne bunyavirus in China. Curr. Opin. Virol. 16, 126-131. doi: 10.1016/j.coviro.2016.02.006

Zhang, Y. Z., Zhou, D. J., Qin, X. C., Tian, J. H., Xiong, Y., Wang, J. B., et al. (2012b). The ecology, genetic diversity, and phylogeny of Huaiyangshan virus in China. J. Virol. 86, 2864-2868. doi: 10.1128/JVI.061 $92-11$

Conflict of Interest Statement: The authors declare that the research was conducted in the absence of any commercial or financial relationships that could be construed as a potential conflict of interest.

Copyright (® 2017 Mansfield, Jizhou, Phipps and Johnson. This is an open-access article distributed under the terms of the Creative Commons Attribution License (CC BY). The use, distribution or reproduction in other forums is permitted, provided the original author(s) or licensor are credited and that the original publication in this journal is cited, in accordance with accepted academic practice. No use, distribution or reproduction is permitted which does not comply with these terms. 